\title{
DESAIN SISTEM PENGATUR LAMPU LALU LINTAS DENGAN IDENTIFIKASI KEPADATAN KENDARAAN MENGGUNAKAN METODE SUBTRACTION
}

\author{
Geminiesty Lathifasari Djavendra*, Siti Aisyah*, Eko Rudiawan Jamzuri \\ Program Studi Teknik Mekatronika, Jurusan Teknik Elektro, Politeknik Negeri Batam \\ *Corresponding author, e-mail: geminiesty@gmail.com,siti_aisyah@polibatam.ac.id
}

\begin{abstract}
Abstrak - Bertambahnya jumlah kendaraan menyebabkan meningkatnya kepadatan lalu lintas yang menjadi salah satu faktor utama penyebab kemacetan. Kepadatan lalu lintas biasanya teralokasi di beberapa titik-titik tertentu di ruas jalan, salah satunya di persimpangan. Saat ini lalu lintas di persimpangan jalan diatur oleh lampu lalu lintas menggunakan sistem prediksi kepadatan lalu lintas. Sistem prediksi ini nantinya akan menentukan lama aktifnya lampu hijau dan lampu merah di setiap persimpangan. Salah satu sistem prediksi yang banyak digunakan adalah metode estimasi stastistik kepadatan kendaraan. Metode lain pengontrolan kepadatan lalu lintas seperti sistem pemantauan secara visual memungkinkan untuk diterapkan guna menambah performansi sistem. Untuk itu penelitian ini mengusulkan pembuatan sebuah sistem pengontrolan lampu lalu lintas secara otomatis dengan prediksi kepadatan kendaraan menggunakan teknik pengolahan citra. Sistem yang dibangun menggunakan kamera untuk memantau kondisi kendaraan di jalan raya. Data gambar yang didapat dari kamera kemudian diolah menggunakan teknik pengolahan citra dan teknik pengurangan citra. Teknik ini membandingkan citra objek dengan citra referensi sehingga dapat diketahui jumlah piksel putih pada citra hasil pengurangan citra. Berdasarkan jumlah piksel putih yang telah diperoleh tersebut dapat diketahui persentase panjang antrian kendaraan dan kepadatan kendaraan. Data persentase yang diperoleh kemudian dikirim ke mikrokontroler untuk mengontrol durasi nyala lampu hijau. Pengontrolan lampu lalu lintas dengan perhitungan kepadatan kendaraan memiliki akurasi hingga $77.03 \%$ sedangkan dengan perhitungan panjang antrian kendaraan mencapai $91.18 \%$.
\end{abstract}

Kata Kunci : Pengolahan citra, pengurangan citra, sistem kontrol lampu, kepadatan kendaraan, dilation, erosion

\begin{abstract}
The increasing number of vehicle causes the increasing of traffic density in which one of the main factors of congestion. Traffic density is usually alocated at certain points of roads, one at the instersection. In the novel technology, traffic in the crossroads had been controlled by traffic light using a traffic density prediction system. This prediction system would determine the duration of active green lights and red lights at each intersection. One of the most common prediction systems is a statistical estimation of vehicle density. Other method at controlling traffic density such as visually monitoring system might be implemented to increase system performance. Therefore, this research proposes an automatically traffic control system by predicting traffic density using image processing techniques. The proposed system is using a camera to visually monitor traffic condition. The image data obtained from the camera would be processed using an image processing and background subtraction techniques. This technique compared an the captured-image with a reference image to result a subtracted-image depicted the traffic density which is represented by the number of white pixels. Based on the number of white pixels that have been obtained, the percentage of vehicle queue length and vehicle density can be determine. The percentage then sent to the microcontroller in order to control the duration of the active green light. The traffic light control system using traffic density calculation has an accuracy of up to $77.03 \%$ while using the calculation of vehicle queue length reached $91.18 \%$.
\end{abstract}

Keywords : Image processing, image subtraction, light control system, traffic density, dilation, erosion

\section{Pendahuluan}

Di era modern saat ini, lalu lintas menjadi hal yang sangat penting agar mobilitas manusia tidak mengalami gangguan. Seiring dengan meningkatnya keperluan dan kesibukan masyarakat agar dapat menjangkau suatu tempat dengan cepat menyebabkan kendaraan menjadi kebutuhan primer bagi sebagian besar masyarakat khususnya yang tinggal di kota - kota besar. Hal tersebut berdampak pada peningkatan 
jumlah kendaraan setiap tahunnya. Peningkatan tersebut secara otomatis dapat mengakibatkan kemacetan di jalan raya. Selain itu, pengontrolan lampu lalu lintas yang kurang efisien dapat menjadi salah satu penyebab kemacetan. Durasi pengontrolan lampu lalu lintas yang konstan dapat menyebabkan timbulnya kemacetan di jalur yang padat apabila jalur lain dalam kondisi sepi atau kosong.

Pengontrolan lampu lalu lintas yang efisien menjadi salah satu solusi untuk meminimalisir kemacetan yang ada dijalan raya. Pengawasan kemacetan dapat dilakukan dengan memanfaatkan kamera sebagai detektor kemacetan di jalan raya yang dipasang disetiap simpang [1]. Data yang didapat dari kamera akan diolah dan nantinya akan digunakan sebagai data untuk mengontrol nyala lampu lalu lintas secara otomatis. Sistem pengaturan lampu lalu lintas ini bekerja berdasarkan masukan berupa gambar hasil capture yang diolah menggunakan metode pengolahan citra, dimana gambar diproses dari format RGB menjadi grayscale, thresholding dan histogram [1].

Penelitian lain memproses gambar menggunakan teknik edge detection untuk mendeteksi kendaraan dan image matching untuk mendapatkan persentase kondisi jalan sehingga dapat mengontrol durasi nyala lampu lalu lintas dengan akurasi 93,47\% [2]. Metode green colour subtraction juga telah digunakan untuk dapat mengetahui kondisi kepadatan kendaraan [3].

Penggunaan background subtraction untuk memperoleh data volume kendaraan juga telah diterapkan pada Raspberry Pi dengan tingkat akurasi metode mencapai 87,6\% [4]. Hanya saja, penelitian tersebut menerapkan metode subtraction dan juga metode contour feature untuk deteksi kendaraan. Metode deteksi objek, termasuk objek kendaraan, juga dapat dilakukan menggunakan metode kecerdasan buatan. Penerapan salah satu metode kecerdasan buatan yaitu algoritma backpropagation dikombinasi dengan metode pengolahan citra untuk deteksi objek terbukti cukup akurat dengan tingkat keberhasilan identifikasi dan deteksi hingga mencapai $99.02 \%$ [5].

Metode yang diusulkan pada penelitian ini adalah metode pengolahan citra (smoothing, erosion dan dilation) dikombinasi dengan background subtraction untuk mendeteksi objek kendaraan dengan menggunakan satu kamera untuk semua simpang. Secara hardware, sistem ini terdiri atas beberapa bagian, antara lain kamera yang berfungsi untuk memantau kondisi jalan, lalu hasil pengamatan diolah di PC menggunakan metode pengolahan citra sehingga didapatkan jumlah piksel putih untuk mengetahui persentase panjang antrian dan kepadatan kendaraan di setiap jalur jalan. Kemudian data persentase dikirim ke mikrokontroler ATMega328 yang berfungsi sebagai piranti untuk mengontrol setiap perubahan lampu lalu lintas di setiap simpang.

\section{Tinjauan Pustaka}

Pengolahan citra merupakan suatu metode yang digunakan untuk mengolah gambar sehingga menghasilkan gambar yang sesuai dengan yang diinginkan. Pengambilan gambar dalam pengolahan citra ini dapat dilakukan dengan menggunakan gambar dari berkas yang sudah ada, ataupun dengan menggunakan kamera.

Citra merupakan kumpulan piksel yang disusun dalam larik dua dimensi. Indeks baris dan kolom (x,y) dari sebuah piksel dinyatakan dalam bilangan bulat. Piksel $(0,0)$ terletak pada sudut kiri atas pada citra, indeks $x$ bergerak ke kanan dan indeks y bergerak kebawah.

\subsection{Grayscale}

Dalam pengolahan citra, grayscale merupakan suatu citra yang hanya memiliki satu nilai warna pada setiap piksel-nya, dimana warna dari grayscale adalah warna keabuan yang berada diantara hitam dan putih, dengan kata lain nilai red $=$ green $=$ blue . Sistem warna grayscale digunakan karena pada proses threshold, citra yang dapat diproses adalah citra dengan derajat keabuan atau disebut dengan grayscale [6]. Persamaan 1 merupakan rumus untuk mendapatkan nilai grayscale dari citra RGB.

$$
I_{\text {Gray }}(x, y)=0.299 I_{R}(x, y)+0.587 I_{G}(x, y)+0.114 I_{B}(x, y)
$$

dengan $I_{\text {Gray }}(x, y)$ merupakan hasil luaran grayscale, sedangkan $I_{R}(x, y)$ merupakan piksel red pada citra, $I_{G}(x, y)$ merupakan piksel green pada citra dan $I_{B}(x, y)$ merupakan piksel blue pada citra.

\subsection{Smoothing}

Smoothing atau sering disebut blurring adalah salah satu teknik dalam pengolahan citra yang digunakan untuk 
mengurangi noise pada suatu citra objek. Pada sistem pengolahan citra, seringkali gambar yang ditangkap oleh perangkat kamera tidak fokus. Hal ini terjadi salah satunya dikarenakan perubahan objek gambar yang menyebabkan munculnya noise. Oleh karena itu, dengan menggunakan teknik blurring ini akan menghapus detail - detail kecil dari gambar. Salah satu teknik blurring yang banyak digunakan yaitu average yang dinyatakan pada persamaan 2 [7].

$$
O(x, y)=\frac{1}{M} \sum_{i=1}^{M} u_{i}(x, y)
$$

dengan $O$ menyatakan citra luaran, $M$ menyatakan banyak matrik, sedangkan $u$ menyatakan citra ke- $i$.

\subsection{Subtraction}

Subtraction merupakan suatu proses pengurangan dua buah citra untuk mengidentifikasi beda kedua citra. Sebagian menggunakan metode ini untuk mengenali objek bergerak. Konsep dari metode ini adalah mengidentifikasi sebuah citra yang disebut background image (citra tanpa objek) dan membandingkannya dengan foreground image (citra dengan objek) untuk mendeteksi objek seperti ditunjukkan pada persamaan 3. Hasil pengurangan piksel pada foreground image dengan background image secara absolut akan selalu menghasilkan nilai positif [8].

$$
R(x, y)=I(x, y)-B(x, y)
$$

dengan $R(x, y)$ merupakan hasil dari pengolahan subtraction, $I(x, y)$ merupakan piksel citra objek atau foreground image, sedangkan $B(x, y)$ merupakan piksel citra background image.

\subsection{Threshold}

Threshold merupakan nilai batas ambang untuk membagi sebuah citra menjadi dua kondisi yaitu foreground dan background. Di dalam teknik pengolahan citra, threshold dapat digunakan sebagai nilai penentu dalam mengubah citra gray menjadi citra binary. Didalam proses perubahan citra grayscale ke citra binary, piksel yang memiliki nilai lebih atau sama dengan nilai ambangnya akan bernilai 255 (berwarna putih), sedangkan jika nilai piksel lebih kecil dari nilai ambang maka nilai citra piksel adalah 0 (berwarna hitam) seperti ditunjukkan pada persamaan 4 [9].

$$
I_{\text {Threshold }}(x, y)= \begin{cases}0 & I_{\operatorname{Gray}(x, y)<T} \\ 255 & I_{\operatorname{Gray}(x, y) \geq T}\end{cases}
$$

dengan $I_{\text {Threshold }}(x, y)$ merupakan hasil luaran citra setelah di threshold, sedang $T$ merupakan nilai ambang yang akan digunakan.

\subsection{Erosion}

Erosion merupakan suatu proses yang berfungsi untuk memindahkan atau mengurangkan piksel pada batas dari suatu objek citra, sehingga objek akan tampak mengecil. Proses erosion dilakukan dengan membandingkan setiap piksel citra dengan nilai pusat $S E$ (Structuring Elements) dengan cara melapiskan $S E$ dengan citra sehingga pusat $S E$ tepat dengan posisi piksel citra yang diproses. Dalam citra binary, jika semua piksel pada $S E$ tepat sama dengan semua nilai objek citra maka piksel diatur nilainya sama dengan nilai piksel objek, bila tidak maka piksel diberi nilai sesuai dengan piksel background seperti ditunjukkan pada persamaan 5 [9].

$$
D(A, B)=A \theta B=\left\{x: B_{x} \subset A\right\}
$$

$A \Theta B$ adalah operasi erosi A dengan $\mathrm{B}$.

\subsection{Dilation}

Dilation adalah suatu proses yang berfungsi untuk menambahkan piksel pada batas dari suatu objek citra, sehingga objek akan terlihat semakin besar. Proses dilation dilakukan dengan membandingkan setiap piksel citra dengan nilai pusat SE (Structuring Elements) dengan cara melapiskan $S E$ dengan citra sehingga pusat $S E$ tepat dengan posisi piksel citra yang diproses. Dalam citra binary, jika paling sedikit terdapat 1 piksel pada $S E$ sama dengan nilai objek citra maka piksel diatur nilainya sesuai dengan nilai piksel objek dan bila semua piksel yang berhubungan adalah background maka piksel diberi nilai sesuai dengan piksel background seperti ditunjukkan pada persamaan 6 [9].

$$
D(A, B)=A \oplus B=\left\{x: B_{x} \cap A \neq \emptyset\right\}
$$

$\emptyset$ menyatakan himpunan kosong. Suatu objek (masukan citra) dinyatakan dengan $A$ dan $S E$ dinyatakan dengan $B . B_{x}$ menyatakan translasi $B$ sedemikian sehingga pusat $B$ terletak pada $x$. $A \oplus B$ adalah operasi dilasi $A$ dengan $B$. 


\section{Metoda}

Pada penelitian ini, digunakan beberapa perangkat keras untuk mendukung proses kerja sistem agar dapat berjalan dengan baik dan perangkat lunak yang berperan penting untuk mengontrol dan memonitoring sistem. Perangkat keras yang digunakan yaitu sensor kamera yang berfungsi untuk menangkap gambar kondisi kendaraan di jalan raya. Dimana kamera yang digunakan adalah kamera Logitech HD Webcam C270. Gambar yang telah didapat kemudian diterima dan diolah oleh PC menggunakan metode pengolahan citra. Metode ini berfungsi untuk mendapatkan nilai persentase kepadatan dan panjang antrian kendaraan. PC terhubung langsung ke mikrokontroler Arduino Uno melalui serial port. Mikrokontroler Arduino Uno berfungsi untuk memberikan sinyal perubahan pada lampu lalu lintas. Sistem yang dibangun diperlihatkan pada gambar 1 .

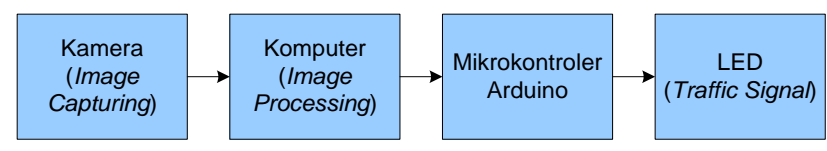

Gambar 1. Diagram blok sistem pengaturan lampu lalu lintas dengan metode pengolahan citra

Metode pengolahan citra dilakukan melalui 2 tahap yaitu:

a. Pengolahan citra referensi

Citra referensi yaitu citra yang didapat saat kondisi jalan kosong atau tidak ada kendaraan. Proses pengambilan citra referensi dilakukan ditahap awal dan ditetapkan sebagai background image. Setelah itu resize citra referensi sesuai dengan ukuran yang ditentukan, lalu menyimpan citra tersebut ke dalam format bitmap (bmp). Kemudian dilanjutkan dengan proses pointing area disetiap simpang sebagai batas area untuk mengetahui kondisi jalan pada citra referensi. Setelah itu, data koordinat area yang telah ditentukan disimpan ke file ini yang telah disediakan. Proses pengolahan citra referensi dapat dilihat dalam diagram alir gambar 2 .

b. Pengolahan citra objek

Proses awal pada tahap kedua yaitu mengambil data referensi yang telah disimpan sebelumnya berupa citra referensi dalam format bitmap (bmp) dan data koordinat piksel disemua simpang. Citra referensi yang di-load dikonversi menjadi citra grayscale. Selanjutnya mengaktifkan kamera untuk mengambil citra objek atau foreground image secara realtime. Citra objek yang telah didapat kemudian diubah ukurannya. Citra objek yang telah didapat kemudian di-smoothing menggunakan teknik average. Teknik ini berfungsi untuk mengurangi noise akibat pengambilan gambar yang tidak fokus menggunakan kamera. Selanjutnya merubah citra objek RGB menjadi citra grayscale yang berfungsi agar citra dapat diimplementasikan pada proses threshold.

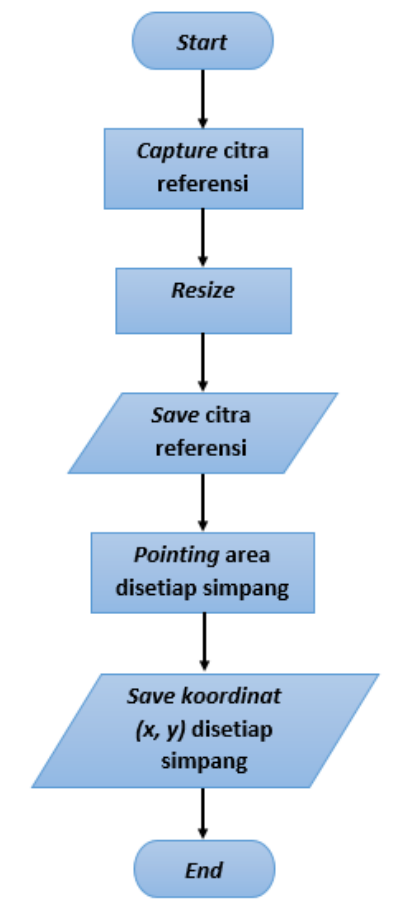

Gambar 2. Urutan pengolahan citra referensi

Berikutnya melakukan proses subtraction yang berfungsi untuk mendapatkan citra objek, dimana citra objek didapat dari hasil pengurangan piksel dari foreground image (citra dengan kondisi jalan terdapat kendaraan) dengan background image (citra dengan kondisi jalan kosong). Setelah dilakukan proses subtraction, citra akan dikonversi menjadi citra binary dengan teknik threshold. Setelah dilakukan proses binary selanjutnya dilakukan proses erosion dan dilation. Erosion berfungsi untuk mengikis piksel citra yang tidak menyatu pada piksel citra objek, akan tetapi pada proses ini piksel pada citra objek akan ikut terkikis sehingga perlu dilakukan proses dilation untuk memulihkan piksel pada citra objek yang terkikis. Dimana dilation berfungsi untuk memulihkan bagian-bagian tepi yang kosong pada citra objek. Selanjutnya 
dilakukan proses get white pixels disetiap disimpang, sehingga dapat diketahui nilai persentase panjang antrian dan kepadatan kendaraan. Data persentase tersebut akan dijadikan masukan untuk mengontrol durasi nyala lampu hijau pada lampu lalu lintas. Diagram alir lengkap proses pengolahan citra objek diperlihatkan pada gambar 3.

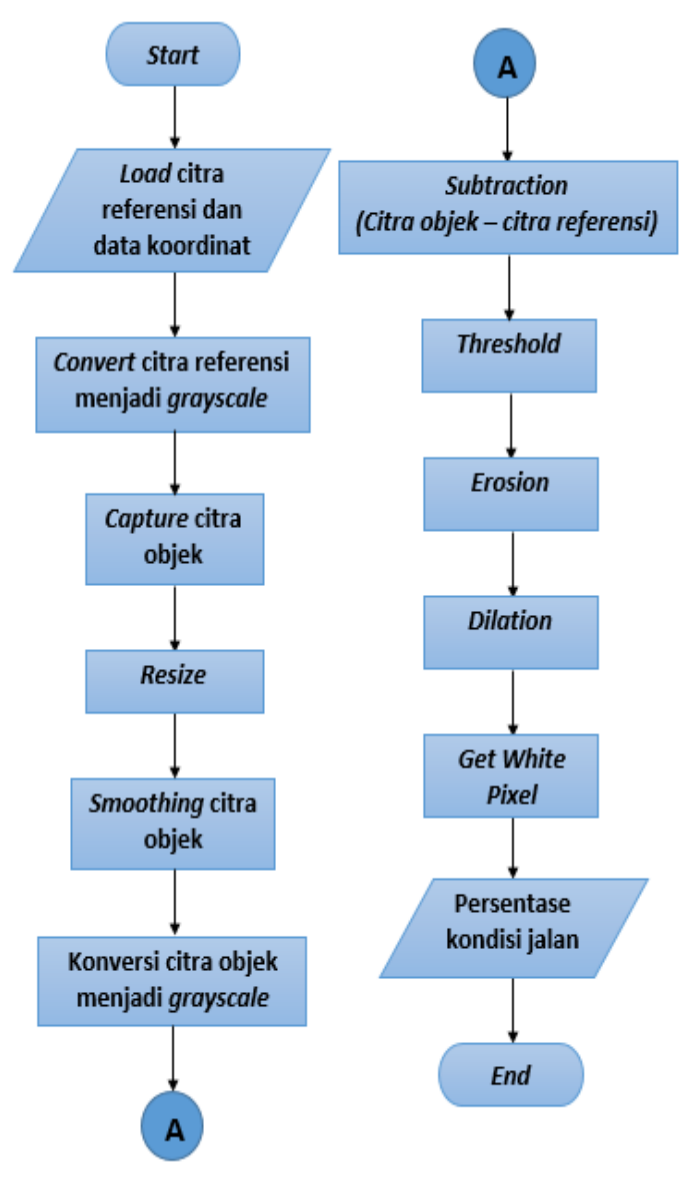

Gambar 3. Urutan pengolahan citra objek

Pengontrolan nyala lampu hijau pada mikrokontroler berdasarkan data persentase yang telah didapat dari hasil pengolahan citra ditentukan dengan durasi nyala lampu hijau minimun dan maksimum masing - masing 3 dan 20 detik. Adapun algoritma lengkap dijelaskan pada pseudocode berikut:

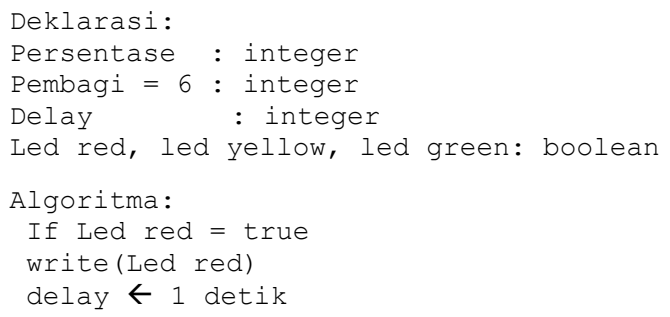

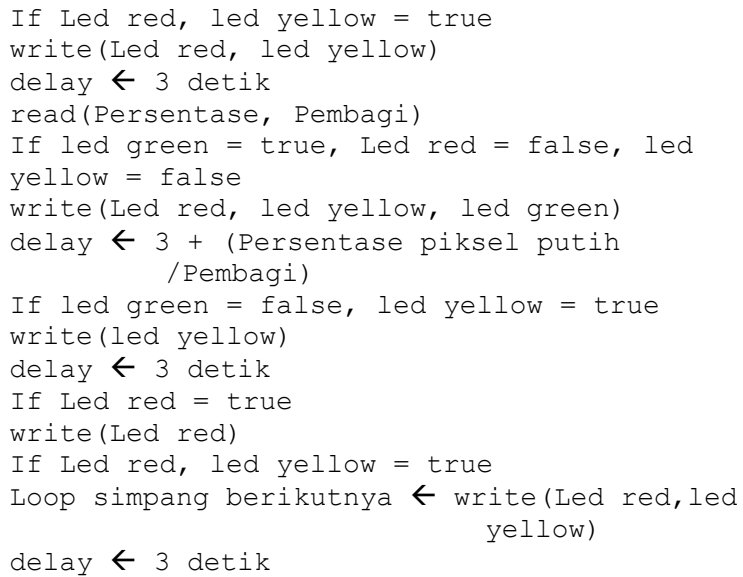

Berdasarkan algoritma pengontrolan durasi nyala lampu hijau, dapat diketahui jika kondisi jalan kosong durasi lama nyala lampu hijau adalah 3 detik, sedangkan jika terdapat kendaraan maka durasi nyala lampu hijau yaitu 3 ditambah dengan (persentase piksel putih / 6), sehingga saat jalan dalam kondisi padat durasi nyala lampu hijau maksimum 20 detik.

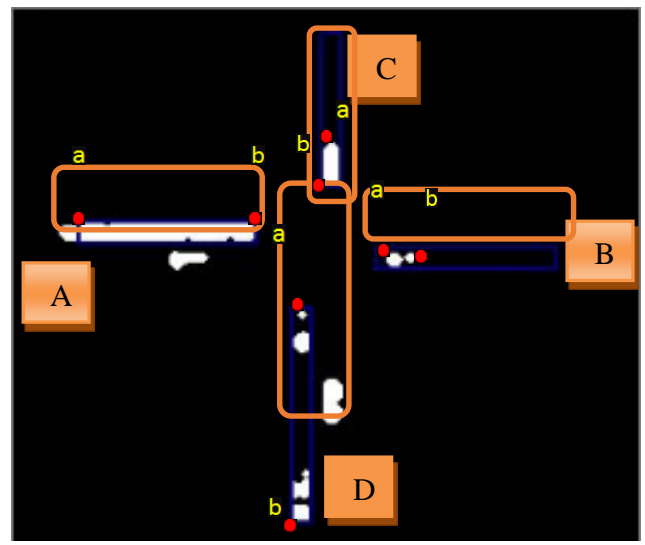

Gambar 4. Hasil simulasi sistem dengan tampilan piksel putih di setiap simpang

Gambar 4 menunjukkan tampilan simulasi penelitian yang telah dilakukan, dimana banyaknya jumlah piksel didalam area rectangle (dibatasi garis biru) pada simpang:
A (Kiri)
: 12 x 91 Piksel
B (Kanan) : 14 x 91 Piksel
C (Atas) : $79 \times 12$ Piksel
D (Bawah) : $111 \times 12$ Piksel

a) Metode Kepadatan Kendaraan

Metode kepadatan kendaraan menggunakan rumus 7 .

Persentase kepadatan $=\frac{\text { total } \text { iksel } \text { putih } \times 100}{\text { luas area rectangle }}$ 
Pada piksel citra binary dengan ukuran $7 \times 6$ seperti ditunjukkan pada gambar 5, dilakukan proses scan line di area rectangle sehingga diperoleh banyaknya piksel putih (nilai 255) yaitu 24 piksel, dengan perhitungan:

$$
\text { Persentase kepadatan }=\frac{24 \times 100}{42}=57.14 \%
$$

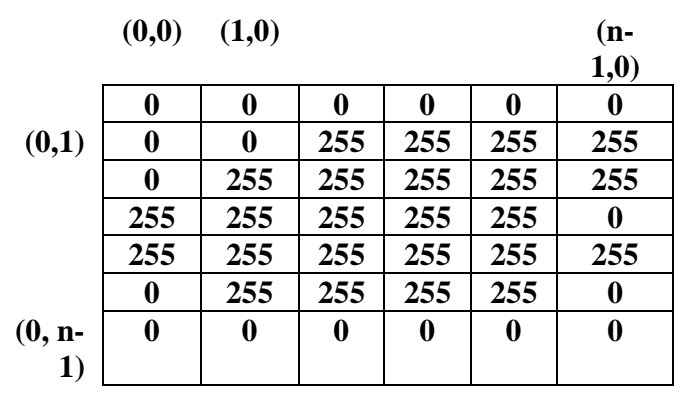

Gambar 5. Piksel citra biner dengan ukuran $7 \mathrm{x}$ 6 untuk perhitungan kepadatan kendaraan

b) Metode Panjang Antrian Kendaraan

Untuk mendapatkan persentase panjang antrian kendaraan digunakan rumus 8 .

Persentase panjang antrian $=\frac{\text { panjang piksel putih } \times 100}{\text { panjang area rectangle }}$

Diambil contoh piksel citra binary dengan resolusi 9 x 5, kemudian dilakukan proses scan line di area rectangle sehingga diperoleh panjang piksel putih sebanyak 9 piksel. Dimana titik a berada pada piksel $(0,1)$ dan titik b pada piksel $(0,6)$, maka panjang piksel putih adalah $6-1=5$. Dengan demikian dapat dihitung persentase panjang antrian sebagai berikut:

Persentase panjang antrian $=\frac{5 \times 100}{9}=55.5 \%$

\begin{tabular}{|c|c|c|c|c|c|}
\hline & $(\mathbf{0 , 0})$ & $(1,0)$ & & & $\begin{array}{l}(\mathbf{n}- \\
\mathbf{1 , 0})\end{array}$ \\
\hline \multirow{8}{*}{$(\mathbf{0 , 1})$} & 0 & 0 & 0 & 0 & $\mathbf{0}$ \\
\hline & (0 & $\mathbf{0}$ & $\mathbf{0}$ & 255 & 255 \\
\hline & 0 & 0 & 0 & $\mathbf{0}$ & $\mathbf{0}$ \\
\hline & 0 & 255 & 255 & 255 & 255 \\
\hline & 255 & 255 & 255 & 255 & 255 \\
\hline & 255 & 255 & $\mathbf{0}$ & $\mathbf{0}$ & 255 \\
\hline & $\mathbf{0}$ & 255 & 0 & 255 & 255 \\
\hline & $\begin{array}{l}\mathbf{0} \\
\end{array}$ & $\mathbf{0}$ & $\begin{array}{l}\mathbf{0} \\
\end{array}$ & $\mathbf{0}$ & $\mathbf{0}$ \\
\hline $\begin{array}{r}(0, n- \\
1)\end{array}$ & 0 & O & 0 & $\mathbf{0}$ & 0 \\
\hline
\end{tabular}

Gambar 6. Piksel citra biner dengan ukuran $9 x$ 5 untuk perhitungan panjang antrian kendaraan

\section{Hasil dan Pembahasan}

Pengujian sistem pada penelitian ini menggunakan citra Gambar 4, dengan rectangle biru berfungsi sebagai batas area untuk mengetahui persentase kepadatan ataupun panjang antrian berdasarkan jumlah piksel putih yang berada didalam area tersebut.

\subsection{Pengujian Sistem Berdasarkan Perhitungan Kepadatan Kendaraan}

Pengujian sistem dengan perhitungan kepadatan kendaraan dilakukan dengan proses scan line pada area rectangle dan menghitung jumlah piksel putih pada area tersebut. Dari pengujian diperoleh jumlah piksel putih untuk area:

kiri : 843 piksel

kanan : 72 piksel

atas : 177 piksel

bawah : 236 piksel

\subsection{Pengujian Sistem Berdasarkan \\ Perhitungan Panjang Antrian Kendaraan}

Untuk mendapatkan nilai persentase panjang antrian kendaraan, dilakukan proses scan line hingga didapatkan piksel putih (get white pixels) didalam area rectangle. Pada simpang atas dan bawah, proses get white pixels dilakukan berdasarkan sumbu y sedangkan pada simpang kiri dan kanan proses get white pixels dilakukan berdasarkan sumbu x. Pada simpang atas dan bawah proses scan line dilakukan dari piksel yminimum $(0,0)$ yang bergerak terhadap sumbu $\mathrm{x}$ didalam area rectangle. Apabila saat proses scan line, piksel putih pertama terdeteksi maka titik a akan menyimpan panjang piksel $\mathrm{y}$, kemudian proses pergerakan scan line berpindah ke piksel y-maksimum $(0, n-1)$ yang bergerak menuju piksel y-minimum terhadap sumbu x pada area rectangle. Apabila saat proses scan line, piksel putih terdeteksi maka titik b akan menyimpan panjang piksel y. Sehingga dapat diketahui panjang piksel putih dengan mengurangi piksel pada titik $\mathrm{b}$ dengan piksel pada titik a (titik b titik a).

Dari hasil pengujian yang dilakukan, banyaknya jumlah piksel putih untuk area: 


\section{Kiri : 90 Piksel Kanan : 15 Piksel \\ Atas : 22 Piksel Bawah : 107 Piksel}

Dari percobaan yang telah dilakukan dapat dilihat hasil persentase kondisi kendaraan dijalan berdasarkan panjang antrian kendaraan dan kepadataan kendaraan pada tabel 1. Pada penelitian ini telah diuji bahwa jumlah mobil yang dapat masuk pada area rectangle yang telah ditentukan yaitu 4 mobil dengan ukuran sama, dengan asumsi ada jarak antar mobil. Sehingga persentase kepadatan kendaraan pada area rectangle akan mencapai $100 \%$ jika terdapat lebih dari 4 mobil.

Untuk mengetahui akurasi data yang telah didapat pada tabel 1, maka dibutuhkan data persentase kondisi kendaraan dijalan secara real pada perancangan alat yang telah dibuat. Data persentase kendaraan secara real dapat dilihat pada tabel 2 .

Dari data tabel 1 dapat diketahui bahwa hasil simulasi menggunakan metode panjang antrian kendaraan lebih baik dibandingkan metode kepadatan kendaraan. Untuk kondisi nomor 1 pada tabel 1 , apabila terdapat 1 mobil didalam area rectangle maka data persentase panjang antrian adalah $22 \%$, sedangkan persentase kepadatan adalah $16 \%$. Jika dibandingkan dengan data persentase secara real pada tabel 2 , nilai persentase panjang antrian kendaraan dan kepadatan kendaraan saat kondisi jalan sepi masing - masing adalah $23.44 \%$ dan $20.51 \%$, sehingga nilai rata - rata akurasi yang didapat dari 10 kali percobaan yang dilakukan yaitu masing masing $91.18 \%$ dan $77.03 \%$.

Tabel 1. Data pensentase kepadatan lalu lintas berdasarkan metode panjang antrian dan kepadatan kendaraan dengan kontrol durasi nyala lampu hijau

\begin{tabular}{|c|c|c|c|c|c|c|}
\hline \multirow[b]{2}{*}{ No } & \multirow[b]{2}{*}{$\begin{array}{c}\text { Simpan } \\
\mathrm{g}\end{array}$} & \multirow[b]{2}{*}{$\begin{array}{c}\text { Kondis } \\
\mathrm{i}\end{array}$} & \multicolumn{2}{|c|}{$\begin{array}{c}\text { Metode Panjang } \\
\text { Antrian }\end{array}$} & \multicolumn{2}{|c|}{$\begin{array}{c}\text { Metode } \\
\text { Kepadatan }\end{array}$} \\
\hline & & & $\begin{array}{c}\text { Persentase } \\
\text { Panjang } \\
\text { Antrian } \\
(\%)\end{array}$ & $\begin{array}{l}\text { Waktu } \\
\text { Hijau } \\
\text { (detik) }\end{array}$ & $\begin{array}{c}\text { Persent } \\
\text { ase } \\
\text { Kepad } \\
\text { atan } \\
(\%)\end{array}$ & $\begin{array}{c}\text { Waktu } \\
\text { Hijau } \\
\text { (detik) }\end{array}$ \\
\hline \multirow{4}{*}{1} & Kiri & Sepi & 22 & 6 & 16 & 5 \\
\hline & Kanan & Sepi & 23 & 6 & 15 & 5 \\
\hline & Atas & Sepi & 28 & 6 & 23 & 6 \\
\hline & Bawah & Sepi & 0 & 3 & 0 & 3 \\
\hline \multirow{4}{*}{2} & Kiri & Sepi & 22 & 6 & 18 & 6 \\
\hline & Kanan & Padat & 58 & 12 & 41 & 10 \\
\hline & Atas & $\begin{array}{c}\text { Norma } \\
1\end{array}$ & 52 & 11 & 46 & 10 \\
\hline & Bawah & Sepi & 17 & 5 & 10 & 4 \\
\hline \multirow[b]{2}{*}{3} & Kiri & Padat & 71 & 14 & 52 & 11 \\
\hline & Kanan & $\begin{array}{c}\text { Norma } \\
1\end{array}$ & 48 & 11 & 31 & 8 \\
\hline
\end{tabular}

\begin{tabular}{|c|c|c|c|c|c|c|}
\hline \multirow{4}{*}{4} & Atas & Sepi & 0 & 3 & 0 & 3 \\
\cline { 2 - 7 } & Bawah & Padat & 64 & 13 & 37 & 9 \\
\hline \multirow{4}{*}{4} & Kiri & Sepi & 0 & 3 & 0 & 3 \\
\cline { 2 - 7 } & Kanan & Sepi & 0 & 3 & 0 & 3 \\
\cline { 2 - 7 } & Atas & Padat & 75 & 15 & 61 & 12 \\
\cline { 2 - 7 } & Bawah & $\begin{array}{c}\text { Sangat } \\
\text { Padat }\end{array}$ & 85 & 17 & 60 & 11 \\
\hline \multirow{4}{*}{5} & Kiri & $\begin{array}{c}\text { Norma } \\
1\end{array}$ & 45 & 10 & 26 & 7 \\
\cline { 2 - 7 } & Kanan & Sepi & 0 & 3 & 0 & 3 \\
\cline { 2 - 7 } & Atas & $\begin{array}{c}\text { Sangat } \\
\text { Padat }\end{array}$ & 100 & 20 & 82 & 16 \\
\cline { 2 - 7 } & Bawah & $\begin{array}{c}\text { Sangat } \\
\text { Padat }\end{array}$ & 90 & 18 & 56 & 12 \\
\hline
\end{tabular}

Tabel 2. Data real persentase kepadatan lalulintas pada area rectangle dengan simulasi kondisi sepi (1 mobil), normal (2 mobil), padat (3 mobil) dan sangat padat (4 atau lebih mobil)

\begin{tabular}{|c|c|c|}
\hline Kondisi & $\begin{array}{c}\text { Persentase Panjang } \\
\text { Antrian (\%) }\end{array}$ & $\begin{array}{c}\text { Persentase } \\
\text { Kepadatan (\%) }\end{array}$ \\
\hline Sepi & 23.44 & 20.51 \\
\hline Normal & 50 & 43.75 \\
\hline Padat & 76.56 & 66.99 \\
\hline Sangat Padat & 100 & 100 \\
\hline
\end{tabular}

Dari hasil tabel 1 dan 2, dapat dilihat bahwa metode panjang antrian kendaraan lebih presisi jika dibandingkan dengan metode kepadatan kendaraan dengan asumsi jarak antar kendaraan tidak cukup jauh. Hal ini dikarenakan metode panjang antrian akan memprediksi nilai persentase kepadatan kendaraan $100 \%$ jika terdapat kendaraan di posisi minimum dan maksimum area rectangle walaupun di posisi tengah tidak terdapat kendaraan. Kemudian persentase piksel putih pada metode kepadatan kendaraan juga kurang akurat dikarenakan adanya proses filter pengolahan citra berupa dilation dan erosion dan adanya jarak antar kendaraan yang cenderung mengurangi jumlah piksel putih.

\section{Kesimpulan}

Setelah melakukan perencanaan pembuatan, pengujian dan analisa sistem, maka dapat diambil kesimpulan dari sistem kerja alat yaitu sebagai berikut: 
1. Berdasarkan hasil luaran yang dihasilkan, terdapat 2 metode untuk mengetahui persentase kendaraan, yaitu:

a. Menghitung jumlah seluruh piksel putih yang berada didalam area rectangle atau berdasarkan kepadatan.

b. Mendapatkan titik paling atas dan titik paling bawah piksel putih yang berada di area rectangle atau berdasarkan panjang antrian.

2. Tingkat akurasi sistem kendali kepadatan lalu lintas menggunakan perhitungan kepadatan kendaraan dan panjang antrian kendaraan masing-masing mencapai $77.03 \%$ dan $91.18 \%$.

3. Penggunaan metode panjang antrian lebih akurat untuk kondisi kepadatan lalu lintas yang rapat yaitu posisi kendaraan dekat satu dengan yang lainnya.

4. Persentase piksel putih sebagai representasi kepadatan pada metode kepadatan kendaraan tidak cukup akurat dikarenakan adanya proses dilation dan erosion serta adanya jarak antar kendaraan yang cenderung mengurangi jumlah piksel putih.

\section{Daftar Pustaka}

[1] Jatmika Sunu, dan Indra Andiko, Simulasi Pengaturan Lampu Lalu Lintas Berdasarkan Data Image Processing Kepadatan Kendaraan Berbasis Mikrokontroler Atmega16, Jurnal Ilmiah Teknologi dan Informasi ASIA, Vol.8, No.2, pp.81, Agustus 2014.

[2] M. Chandrasekhar, etc., Traffic Control Using Digital Image Processing, International Journal Of Advanced Electrical and Electronics Engineering,Vol.2, No.5, pp.96, 2013.

[3] Gaikwad Omkar Ramdas, etc., Image Processing Based Traffic Light Control, International Journal of Science, Engineering and Technology Research (IJSETR), Vol. 3, Issue 4, April 2014.

[4] Fitria Rahmadina dan Zaini, Sistem Informasi Kepadatan Lalu Lintas Berbasis Raspberry pi PC Board, Jurnal Nasional Teknik Elektro, Vol: 5, No. 1, Maret 2016.
[5] Kasdianto dan Siti Aisyah, Desain Sistem Pendeteksi untuk Citra Base Sub-Assembly dengan Algoritma Backpropagation, Jurnal Rekayasa Elektrika, Vol. 13, No. 1, April 2017, hal. 1-7.

[6] Wan Yi, Xie Qisong, A Novel Framework for Optimal RGB to Grayscale Image Conversion, International Conference on Intelligent Human-Machine Systems and Cybernetics, 2016.

[7] Praba D. Surya daoold \& Kumar J. Satheesh, Performance Analysis of Image Smoothing Methods for Low Level of Distortion, IEEE International Conference on Advances in Computer Applications (ICACA), 2016.

[8] Wang Yuan-Kai, Chen Hung-Yu, The Design of Background Subtraction on Reconfigurable Hardware, Eighth International Conference on Intelligent Information Hiding and Multimedia Signal Processing, IEEE (2012).

[9] Putra Darma, Pengolahan Citra Digital, Penerbit Andi, 2010.

\section{Biodata Penulis}

Geminiesty Lathifasari Djavendra lahir di Pekanbaru tanggal 26 Mei 1996. Menerima gelar Sarjana Sains Terapan dari Jurusan Teknik Elektro Politeknik Negeri Batam tahun 2017.

Siti Aisyah memperoleh gelar Sarjana Teknik dari Institut Teknologi Sepuluh Nopember (ITS) dan gelar Master di The Queens University of Belfast, Northern Ireland, United Kingdom. Bidang penelitiannya meliputi pengolahan citra, wireless telemetry system, IoT, artificial intelligence dan sistem kontrol.

Eko Rudiawan Jamzuri memperoleh gelar Sarjana Sains Terapan dari Institut Teknologi Bandung (ITB) pada tahun 2013. Bidang penelitiannya meliputi robotika, computer vision, artificial intelligence dan factory automation. 